九州大学学術情報リポジトリ

Kyushu University Institutional Repository

\title{
Interspecific Difference in Growth Perenniality in Rice Cultivars, Oryza sativa L. and 0. glaberrima Steud.
}

Kawahara, Teruhiko

Laboratory of Practical Botany, Faculty of Agriculture, Kyushu University

Kubota, Fumitake

Laboratory of Practical Botany, Faculty of Agriculture, Kyushu University

Hirao, Kenji

Laboratory of Practical Botany, Faculty of Agriculture, Kyushu University

Saitou, Kazuyuki

Laboratory of Practical Botany, Faculty of Agriculture, Kyushu University

他

https://doi.org/10.5109/24219

出版情報：九州大学大学院農学研究院紀要. 42 (3/4)，pp.315-323，1998-03. Kyushu University バージョン：

権利関係: 


\title{
Interspecific Difference in Growth Perenniality in Rice Cultivars, Oryza sativa L. and O. glaberrima Steud.
}

\author{
Teruhiko Kawahara, Fumitake Kubota, Kenji Hirao, \\ Kazuyuki Saitou and Waichi Agata \\ Laboratory of Practical Botany, Faculty of Agriculture, Kyushu University, \\ Fukuoka 812-8581, Japan \\ (Received November 10, 1997 and accepted December 3, 1997)
}

\begin{abstract}
Of the two rice cultivar species, Oryza sativa and $O$. glaberrima, the former was predicted as a species with a higher potential in growth perenniality compared to the latter in a previous paper. In this paper we made a further study to confirm the specific difference in growth perenniality by comparing the growth characteristics, leaf photosynthesis and photosynthate partitioning in a plant at the post-heading stage. O. glaberrima was characterized by quick accumulation of photosynthate in the panicles. The simple morphological formation of rachis branching of $O$. glaberrima is thought to allow the smooth transportation of photosynthate from leaves to chaffs of a panicle and the early maturation. Such a feature as observed in O. glaberrima is regarded as an advantageous character for the seed production in annual plants. The photosynthate partition among different organs was monitored by the ${ }^{13} \mathrm{C}$ trace method. The culm base of $O$. sativa accumulated several-fold more ${ }^{1 "} \mathrm{C}$ than that of $O$. glaberrima. The accumulated photosynthate is available as energy resource for initiation of the regenerative growth by ratooning, and the species having a large amount of the accumulation can keep a high potential of growth perenniality.
\end{abstract}

\section{INTRODUCTION}

The two species, Oryza sativa and O. glaberrima, are known as the cultivaral rice species. According to the reports of Morishima et al. $(1961,1963)$, these species originate from wild species, $O$. perennis and $O$. breviligulata, respectively. It is likely that many ecotypes with different growth persistency from annual to perennial are included in $O$. perennis, whereas $O$. breviligulata is regarded as an annual type.

$O$. glaberrima is evaluated as a species with less productivity than $O$. sativa; however, a high stability in production and strong tolerance to environmental stresses are profitable characters in O. glaberrima (Katayama, 1987; Sumi et al., 1994). In addition, this species is more sensitive to nitrogen application, that is, it shows a vigorous growth and elongation when grown in the paddy with a little increased fertilization levels (Sumi et al., 1990; Kubota et al., 1992). Studies on the growth characteristics, photosynthesis, and biomass or yield production have been greatly accumulated for $O$. sativa until now, and frequently these parameters have been discussed in comparison with those of $O$. glaberrima. We are also interested in specific features of them and believe that the most distinguishable difference between $O$. sativa and $O$. glaberrima exists in their growth behavior at the post-heading stage and also in their regenerative growth potential after maturation, but limited information is available concerning this area.

In a previous paper, two species, $O$. sativa and $O$. glaberrima, introduced from West 
Africa were examined on their growth perenniality by comparing their biomass partitioning trait in a plant and ratooning vigor after harvest. From this study, $O$. sativa was predicted to remain genetically a higher potential of growth perenniality. Following this study, we conducted a further study here bringing focus to photosynthesis, evaporation and photosynthate partitions during the post heading stage, in order to obtain more decisive information on the potential of growth perenniality and its specific difference. Of the factors closely related to growth perenniality, the amount of photosynthate in the stock of a plant is important because it is utilized as main energy resource for regenerative growth initiation by ratooning. The photosynthate partition trait in a plant may be adopted as a criterion for evaluating the growth perenniality. We tried here a ${ }^{13} \mathrm{CO}_{2}$ feeding experiment with both species and monitored ${ }^{13} \mathrm{C}$ partitions in a plant.

\section{MATERIALS AND METHODS}

As experimental materials, O. sativa (C-173, a strain listed in the African Rice Collection Record of Kagoshima University, Nakagama et al. 1988) and O. glaberrima (C-174), were used here. For the convenience, the strain numbers of $\mathrm{C}-173$ and $\mathrm{C}-174$ were changed and used below as S-173 and G-174, respectively. Among many genotypes introduced from the neighboring districts by the Niger River of West Africa to Kagoshima University these strains were chosen, through the years long observation of their growth behaviors, to be used as the experimental materials. S-173 and G-174 grown under the climatic condition of Kyushu districts represent their specific characteristics in growth as $O$. sativa and $O$. glaberrima, respectively. The experiments and treatments were conducted in the experimental field of Kyushu University over two years using water and soil culture methods in 1992 and 1993, respectively. The results of the latter experiment were described and discussed here.

A young shoot with 3.5 leaf age was transplanted in a $8.5 \mathrm{~L}$ pot containing sandy loam soil. The total number of plants or pots provided here were 40 for S-173 and G-174 each. As basal fertilization a compound chemical including $\mathrm{N}, \mathrm{P}$ and $\mathrm{K}$ each $0.5 \mathrm{~g}$ in element was applied to a pot. After transplanting, the plants were vigorously grown under adequate fertilization and watering managements for each strain. Particularly, a careful fertilization was required for G-174 because the plant was readily logged by a little too much application of fertilizer.

Four plants of each strain were sampled first at the heading time and then the samplings were conducted four times at 10-day intervals up to the 40th day to investigate the dry matter weight of each organ, leaf area and yield production. The obtained data were used for growth analysis and calculation of the matter partition ratio of the different organs.

On the 15th, 25th and 30th days after heading, $\mathrm{CO}_{2}$ exchange rates (CER) were measured on the first (flag), second and third leaves of both strains in the mornings with a portable photosynthesis and evaporation system (SPB-H3, ADC, UK). A slide projector (HILUX-HR, Rikagaku, Japan) was used as the light source, and air temperature in the assimilation chamber was at $30.0 \pm 1.0^{\circ} \mathrm{C}$. In addition, the diurnal changes in CER of both strains and climatic factors were monitored in a clear day under the field condition on the 
15 th day.

The photosynthate partitions in a plant were investigated using ${ }^{13} \mathrm{CO}_{2}$-fed plants. A pot-grown plant was enclosed in an assimilation chamber with a capacity of $37 \mathrm{~cm} \times 27 \mathrm{~cm}$ $\times 116 \mathrm{~cm}$, then the assimilation chamber was filled with ${ }^{19} \mathrm{CO}_{2}$ so that the plant placed inside absorbed it by photosynthesis. ${ }^{13} \mathrm{CO}_{2}$ was produced by applying $10 \mathrm{ml}$ of $1 \mathrm{~N} \mathrm{HCl}$ to $1 \mathrm{~g}$ of ${ }^{13} \mathrm{C}$ labeled barium carbonate $\left(\mathrm{Ba}^{13} \mathrm{CO}_{3}\right)$ put in a $50 \mathrm{ml}$ beaker fixed in the assimilation chamber. After this treatment, the $\mathrm{CO}_{2}$ concentration came up to about $1,500 \mu \mathrm{LL}^{-1}$ and then the concentration reduction by photosynthesis at high sun light intensities was monitored with the portable $\mathrm{CO}_{2}$ analyzer described above. Cool water was continuously flowed on surfaces of the assimilation chamber during the treatment to prevent a rapid increase in air temperature inside, and an anti-fog liquid was applied on the inside surface of the chamber. The ${ }^{13} \mathrm{CO}_{2}$-feeding experiments for both species were conducted on the heading day then the 10th, 20th and 30th days after heading, and were repeated twice for each case.

After ${ }^{13} \mathrm{CO}_{2}$-feeding the plants were placed under the open condition for 24 hours before sampling. The sampled plants were divided into different organs such as leaf, culm, stock, root and panicle, and they were dried for a week at $80^{\circ} \mathrm{C}$ in a oven. Here culm means the upper part of culm higher than $5 \mathrm{~cm}$ above the ground level, and stock is the culm base, the lower part of culm less than $5 \mathrm{~cm}$. The dried samples were powdered to determine the ratio of ${ }^{13} \mathrm{C}$ to ${ }^{12} \mathrm{C}$ with a ${ }^{13} \mathrm{C}$ analyzer (Nihon Bunko, EX-130S, Japan). From the measurements the photosynthate partition ratio for each organ was calculated.

\section{RESULTS}

\section{Dry matter production and panicle growth}

Both strains represented a vigorous growth after transplanting to pots, with the head emergency at the almost same time, Sept. 9 th for S-173 and Sept. 12th for G-174. Plant heights of S-173 and G-174 reached 102 and $123 \mathrm{~cm}$ and the final plant weights were 76.5

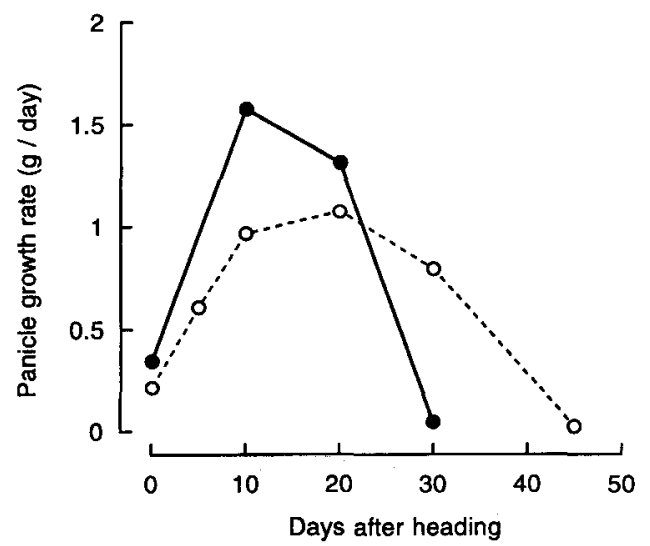

Fig. 1. Changes in panicle growth rate during the post-heading stage in $O$. sativa (S-173) and $O$ glaberrima (G-174). ○, O. sativa; , O. glaberrima 
and $90.6 \mathrm{~g}$, respectively.

The time courses of panicle growth rate were significantly different between the two strains as shown in Fig. 1. In G-174, panicle growth rate quickly increased to the maximum $\left(1.5 \mathrm{~g} \mathrm{~d}^{-1}\right)$ at the 10 th day after heading, then decreased. On the other hand, the rate of S-173 showed a mild mono-peaked curve and the maturing period was longer than that of G-174. The final panicle weights per plant of S-173 and G-174 were 38.7 and $42.0 \mathrm{~g}$, respectively.

\section{Changes in photosynthesis and transpiration with climatic factors}

Fig. 2 represents the time courses of CER of the first (flag), second and third leaves in the two strains during the post-heading stage. CERs of the first and second leaves determined at the heading time were 20.7 and $19.4 \mu \mathrm{molm}^{-2} \mathrm{~s}^{-1}$ in $\mathrm{G}-174$, and 22.1 and $18.6 \mathrm{mmolm}^{-2} \mathrm{~S}^{-1}$ in S-173, respectively. There was no significant difference in photosynthetic potential between the strains, but G-174 showed a more rapid decrease in CER with time during the maturation stage.

Diurnal changes in CER of both strains and climatic factors determined in a clear day

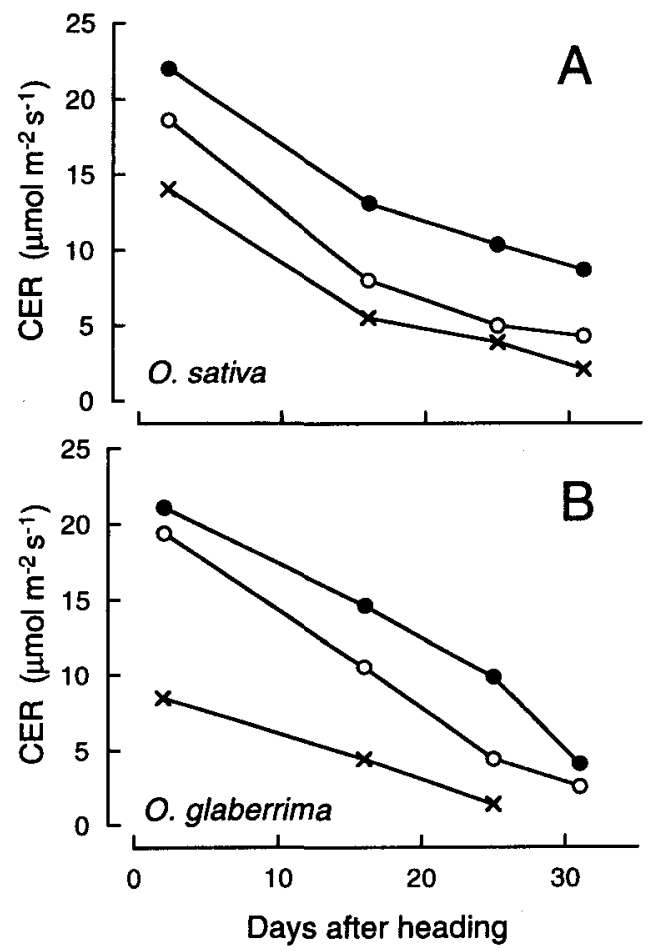

Fig. 2. Changes in $\mathrm{CO}_{2}$ exchange rate (CER) in O. sativa (S-173) and $O$. glaberrima (G-174) during the post-heading stage. , First leaf (flag leaf); $O$, 2nd leaf; $\times$, 3rd leaf. CER was measured at saturating light intensities. 

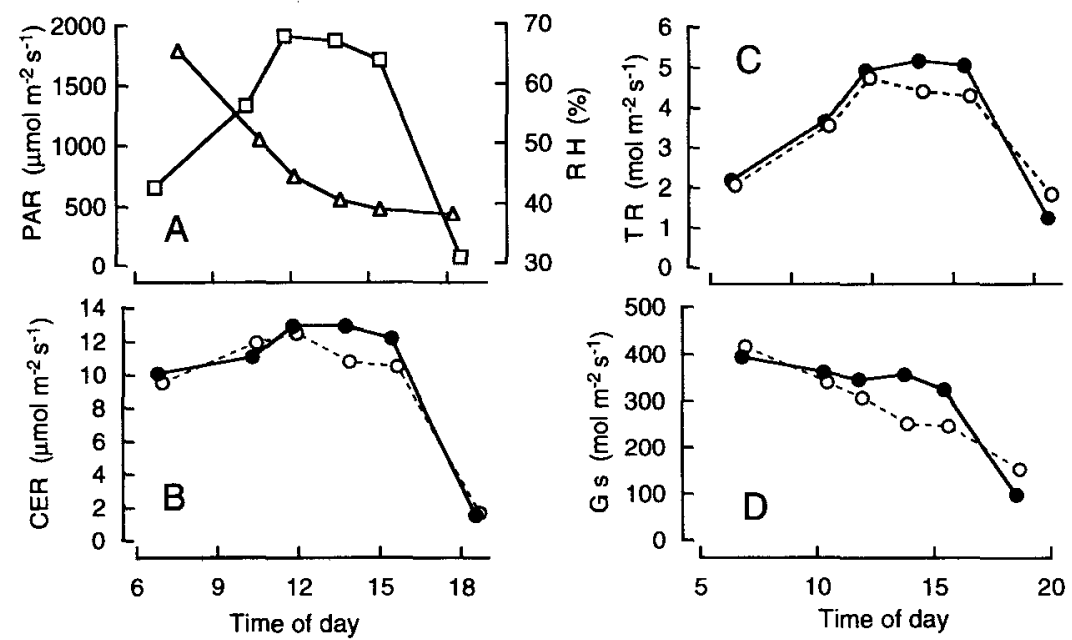

Fig. 3. Diurnal changes in $\mathrm{CO}_{2}$ exchange rate (CER), transpiration rate (TR), stomatal conductance (Gs), photosynthetically active radiation (PAR) and relative humidity (RH) in $O$. sativa (S173) and $O$. glaberrima (G-174). $\square, \mathrm{PAR}, \triangle, \mathrm{RH}, \mathrm{O}, \mathrm{O}$. sativa;, o. glaberrima

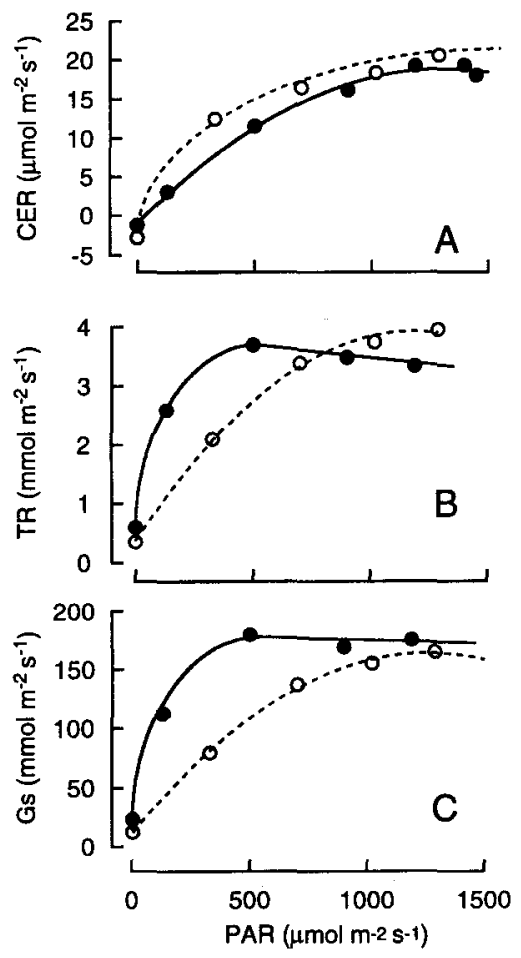

Fig. 4. Changes in $\mathrm{CO}_{2}$ exchange rate (CER), transpiration rate (TR) and stomatal conductance (Gs) with photosynthetically active radiation (PAR) in $O$. sativa (S-173) and O. glaberrima (G-174). O, O. sativa; , O. glaberrima 